\title{
Efficient RNA-based reprogramming of disease-associated primary human fibroblasts into induced pluripotent stem cells
}

\author{
Patrick S. McGrath ${ }^{1,2}$, Shennea S. McGarvey ${ }^{1,2}$, Igor Kogut ${ }^{1,2}$, Ganna Bilousova ${ }^{1,2,3}$ \\ ${ }^{1}$ Department of Dermatology, University of Colorado School of Medicine, Anschutz Medical \\ Campus, Aurora, Colorado, USA \\ ${ }^{2}$ Charles C. Gates Center for Regenerative Medicine, University of Colorado School of Medicine, \\ Anschutz Medical Campus, Aurora, Colorado, USA
}

\begin{abstract}
Reprogramming a patient's somatic cells into induced pluripotent stem cells (iPSCs) holds great promise for disease modeling and the development of autologous cellular therapeutics. However, it remains challenging to consistently reprogram primary human cells, as they are frequently aged, diseased, or in low abundance. Here we present a modified highly efficient and clinically relevant RNA-based method for reprogramming disease-associated and other difficult-to-reprogram human primary fibroblast lines into iPSCs. We also describe optimizations that can be employed for consistent reprogramming of these difficult-to-reprogram cells. With the provided protocol, integration-free iPSC lines can be successfully generated from a small number of primary human fibroblasts in approximately 5-7 weeks.
\end{abstract}

\section{Keywords}

Induced pluripotent stem cells; iPSCs; Reprogramming; Modified mRNA; microRNAs; Primary cells; Human; Fibroblasts; Clinically relevant

\section{Introduction}

It was first shown in 2007 that forced expression of a core set of transcription factors that regulate pluripotency could directly reprogram human somatic cells into induced pluripotent stem cells (iPSCs) [1]. IPSCs have the unique ability to differentiate into any cell type of the body and hold great promise for clinical application. It is therefore critical that the reprogramming factors are only expressed transiently and are nonintegrating to avoid safety risks associated with insertional mutagenesis [2]. The most widely adopted nonintegrating approaches utilize episomal plasmids [3] or Sendai virus [4], but these require lengthy dilution passaging steps to eliminate the vectors, which results in a higher mutational load and increased cost. Transiently expressing reprogramming factors from modified messenger RNAs (mRNAs) has also been used to generate iPSCs from somatic cells [5] although

\footnotetext{
${ }^{3}$ Correspondence: Ganna Bilousova, Charles C. Gates Center for Regenerative Medicine, University of Colorado School of Medicine, Anschutz Medical Campus, P.O. Box 6511, Mail Stop 8320, Aurora, CO 80045. Phone: 303-724-3957; Fax: 303-724-3051;

Ganna.Bilousova@CUAnschutz.edu.
} 
mRNAs alone can be very inefficient for reprogramming difficult-to-transfect primary fibroblasts.

We recently described a highly efficient reprogramming procedure that overcomes many of the inconsistencies associated with mRNA-based reprogramming by optimizing various parameters [6]. In this method, the reprogramming modified mRNA cocktail includes SOX2, KLF4, cMYC, NANOG, LIN28A, and $\mathrm{M}_{3} \mathrm{O}$ (OCT4 fused to the MyoD transactivation domain). Mature miRNA-367/302 mimics, previously shown to induce pluripotency [7], are also included in the cocktail, which synergizes with the reprogramming factors to enhance reprogramming efficiency. Lastly, the transfection reagents and culture conditions were adjusted such that human dermal fibroblasts could be reproducibly transfected with extremely high efficiency. Collectively, the improved method can consistently yield thousands of reprogrammed iPSC colonies from just a single well of a 6-well plate seeded with as few as 500 human fibroblasts [6].

Despite the improved protocol, we still encounter significant line-to-line variability in reprogramming amongst patient-derived fibroblasts. This can be due to age and disease status of the patient or sometimes from excessive handling and extended culture of the primary fibroblasts. We have observed that cell density throughout the reprogramming procedure critically impacts efficiency. Plating the fibroblasts sparsely is important to induce adequate cell cycling, which facilitates reprogramming [8], but this must be balanced with plating cells at a sufficiently high density to maintain overall health of the primary cells without overgrowth during the procedure.

It is usually difficult to predict how any given fibroblast line will behave during reprogramming. For this reason, we now initiate fibroblast reprogramming with a range of plating densities $\left(3 \times 10^{3}, 10 \times 10^{3}\right.$, and $30 \times 10^{3}$ cells per well of a 6 -well plate), one of which will be the ideal density to maximize efficiency. The addition of this step, together with our highly optimized reprogramming protocol using modified mRNAs and miRNAmimics, has yielded high-quality iPSC lines from even the most difficult-to-reprogram fibroblasts on the first attempt. The improved reprogramming protocol and plating procedure is described here using an example of somatic fibroblasts derived from a patient with Down syndrome (Trisomy 21).

\section{Materials}

\subsection{Fibroblast culture}

1. Tissue culture treated $10 \mathrm{~cm}$ dish

2. Fibroblast expansion medium (FEM): Minimum essential medium (MEM) supplemented with 10\% FBS, 1x MEM non-essential amino acids, 1x GlutaMAX, 55 $\mu \mathrm{M}$ 2-mercaptoethanol, 1x Pen/Strep/Fungizone (GE Healthcare). Store at $4^{\circ} \mathrm{C}$.

3. DPBS (no calcium, no magnesium, Thermo Fisher Scientific)

4. Trypsin-EDTA (0.25\%), with Phenol Red (Thermo Fisher Scientific) 
5. Primary human dermal fibroblasts isolated using standard procedures

\subsection{Plating fibroblasts for reprogramming}

1. DPBS (no calcium, no magnesium, Thermo Fisher Scientific)

2. rhLaminin-521 (Thermo Fisher Scientific)

3. FGF Basic (bFGF, Thermo Fisher Scientific)

4. Vaccinia Virus B18R (Carrier-free, Thermo Fisher Scientific)

5. Plating medium: ReproM (see Subheading 2.3, item 1 below) supplemented with $5 \%$ FBS. Add bFGF to a final concentration of $100 \mathrm{ng} / \mathrm{mL}$ and B18R to a final concentration of $200 \mathrm{ng} / \mathrm{mL}$ immediately before use.

\subsection{Reprogramming fibroblasts}

1. Reprogramming medium (ReproM): Dulbecco's Modified Eagle Medium/ Nutrient Mixture F-12 without HEPES (DMEM/F12, Thermo Fisher Scientific) supplemented with 20\% KnockOut Serum Replacement (Thermo Fisher Scientific), 0.5x MEM non-essential amino acids, 0.5x GlutaMAX, $55 \mu \mathrm{M} 2$ mercaptoethanol, $50 \mu \mathrm{g} / \mathrm{mL}$ ascorbic acid, 1x Pen/Strep/Fungizone (GE Healthcare). Store at $4^{\circ} \mathrm{C}$. Add bFGF to a final concentration of $100 \mathrm{ng} / \mathrm{mL}$ and B18R to a final concentration of $200 \mathrm{ng} / \mathrm{mL}$ immediately before each use to an aliquot sized for that day's use.

2. Lipofectamine RNAiMax Transfection Reagent (Thermo Fisher Scientific).

3. Transfection buffer (see Note 1): Adjust the $\mathrm{pH}$ of Opti-MEM (Thermo Fisher Scientific) to 8.2 with $1 \mathrm{M} \mathrm{NaOH}$ as previously described [9]. Filter-sterilize and aliquot the adjusted Opti-MEM into 2-mL tubes with minimal air space. Aliquots can be stored for up to 3 months at $4^{\circ} \mathrm{C}$ or up to 1 year at $-80^{\circ} \mathrm{C}$. Limit aliquot usage to two transfections since the exposure of Opti-MEM to atmospheric air changes the $\mathrm{pH}$ of the buffer.

4. Reprogramming RNA cocktail: a comprehensive procedure for the in vitro transcription of modified mRNA is beyond the scope of this protocol but has been described in depth elsewhere $[5,6,10]$. Prepare the mixture of in vitro transcribed modified mRNAs and micro-RNA (miRNA) mimics as described in Fig. 1. The mRNAs are mixed in a molar ratio of 3:1:1:1:1:1 (M3O-SOX2KLF4-cMYC-NANOG-LIN28A) with an additional 10\% mWasabi modified mRNA to control for transfection efficiency. For each transfection, each well of a 6-well plate is transfected with a total of $1000 \mathrm{ng}$ of modified mRNA and 20 pmol of miRNA ( 4 pmol of each miRNA) diluted in $14 \mu \mathrm{L}$ of nuclease-free water supplemented with $1 \mathrm{U} / \mu \mathrm{L}$ of Riboguard RNase inhibitor (Lucigen). Prepare seven $88 \mu \mathrm{L}$ aliquots and store at $-80^{\circ} \mathrm{C} .88 \mu \mathrm{L}$ is sufficient to reprogram all wells of a 6-well format plate and includes $4 \mu \mathrm{L}$ excess for pipetting error. 


\subsection{Picking iPSC colonies}

1. 6-well plate, tissue culture treated

2. iPSC passaging reagent: Add $500 \mu \mathrm{L}$ of $0.5 \mathrm{M}$ EDTA (pH 8.0) to $500 \mathrm{~mL}$ of DPBS (no calcium, no magnesium). Filter-sterilize using a $0.22 \mu \mathrm{m}$ vacuum filtration system. Store at room temperature.

3. mTeSR1 complete medium (mTeSR, STEMCELL Technologies)

4. Matrigel hESC-Qualified Matrix (LDEV-free, Corning)

\subsection{Equipment}

1. Biological Safety Cabinet.

2. $37^{\circ} \mathrm{C}$ water bath or bead bath.

3. $37{ }^{\circ} \mathrm{C} / 5 \% \mathrm{CO} 2$ humidified tissue culture incubator

4. $37{ }^{\circ} \mathrm{C} / 5 \% \mathrm{CO} 2 / 5 \% \mathrm{O} 2$ humidified trigas tissue culture incubator.

5. Inverted microscope configured to visualize EGFP.

6. Hemocytometer.

7. Centrifuge.

\section{Methods}

Work under RNase-free conditions and use aseptic techniques when possible. Perform all cell culture-related manipulations in a biological safety cabinet using aseptic techniques. Follow institutional biosafety standards for work with human cells. Once the reprogramming procedure is initiated, daily maintenance is required for approximately $30-40$ days. Be sure to plan accordingly.

\subsection{Fibroblast culture}

1. Prewarm $15 \mathrm{~mL}$ of FEM and $3 \mathrm{~mL}$ of trypsin-EDTA to $37^{\circ} \mathrm{C}$.

2. Carefully aspirate the spent cell culture media from the fibroblasts. Rinse the cells once with $5 \mathrm{~mL}$ of DPBS to remove residual serum. Add $3 \mathrm{~mL}$ of trypsinEDTA. Gently rock the plate to ensure complete and even coverage.

3. Aspirate excess trypsin-EDTA off the monolayer, leaving approximately $500 \mu \mathrm{L}$. Do not overaspirate, since this can dry the fibroblasts and kill them. Incubate the fibroblasts with trypsin-EDTA for $3 \mathrm{~min}$ at $37^{\circ} \mathrm{C}$.

4. During incubation, add $10 \mathrm{~mL}$ of prewarmed FEM to a tissue-culture treated 10 $\mathrm{cm}$ dish. Set aside.

5. Remove the plate from the incubator and firmly but gently tap the side of the plate to dislodge cells. Check the cells under the microscope. If the cells are detached and floating, proceed. If the cells are still attached, place them back in the $37^{\circ} \mathrm{C}$ incubator and check every 2 min until detached. 
6. Quickly rinse and collect the detached cells using $5 \mathrm{~mL}$ of prewarmed FEM to neutralize the trypsin-EDTA. Move the fibroblast suspension into a $15 \mathrm{~mL}$ conical tube. Ensure that the cells are well mixed, and then count the cells on a hemocytometer. DO NOT centrifuge the fibroblasts to pellet.

7. After counting, gently but thoroughly resuspend the fibroblasts. Transfer $2.5 \times$ $10^{5}$ cells into the $10 \mathrm{~cm}$ dish with FEM. Incubate the cells overnight in the $37^{\circ} \mathrm{C} / 5 \% \mathrm{CO} 2$ humidified regular tissue culture incubator (see Note 2 ). The remaining fibroblasts can be frozen for long-term storage or discarded.

8. Replace the medium with $10 \mathrm{~mL}$ of fresh FEM the following day (day-1).

\subsection{Plating fibroblasts for reprogramming}

1. Verify that the fibroblasts to be reprogrammed are at a confluency of $40-60 \%$. If the cells are over- or under-confluent, passage the fibroblasts as previously described (Subheading 3.1) and adjust the plating density accordingly. Culture for another 2 days.

2. To prepare a coated 6-well plate for reprogramming, transfer $6 \mathrm{~mL}$ of DPBS into a $15 \mathrm{~mL}$ conical tube. Add $150 \mu \mathrm{L}$ of rhLaminin-521. Pipette up and down to mix thoroughly. Add $1 \mathrm{~mL}$ of diluted rhLaminin-521 into each well of a 6-well plate. Incubate the coated plate at $37^{\circ} \mathrm{C}$ for $2 \mathrm{~h}$.

3. Prewarm $3 \mathrm{~mL}$ of trypsin-EDTA and $20 \mathrm{~mL}$ of plating media supplemented with B18R $(200 \mathrm{ng} / \mathrm{mL})$ and $\mathrm{bFGF}(100 \mathrm{ng} / \mathrm{mL})$ to $37^{\circ} \mathrm{C}$.

4. After $2 \mathrm{~h}$ of incubation, remove the coated plate from the incubator and aspirate diluted rhLaminin-521 from the wells. Do not allow the surface of the wells to dry. Add $1.9 \mathrm{~mL}, 1.7 \mathrm{~mL}$, or $1 \mathrm{~mL}$ of plating media into the appropriate wells as shown in Fig. 2a and set aside.

5. Carefully aspirate the spent medium from the fibroblasts. Rinse the cells with 5 $\mathrm{mL}$ of DPBS and add $3 \mathrm{~mL}$ of trypsin-EDTA. Gently rock the plate to cover the cells with trypsin-EDTA. Aspirate excess trypsin-EDTA, leaving approximately $500 \mu \mathrm{L}$. Take care not to allow the cells to dry. Incubate the fibroblasts with trypsin-EDTA for $3 \mathrm{~min}$ at $37{ }^{\circ} \mathrm{C}$. Remove the plate from the incubator and firmly but gently tap the side of the plate to dislodge cells. Check cells under the microscope. If the cells are detached and floating, proceed. If the cells are still attached, place them back in the $37^{\circ} \mathrm{C}$ incubator and check every 2 min until the cells are detached.

6. Rinse and collect the detached cells using $5 \mathrm{~mL}$ of plating media to neutralize the trypsin-EDTA. Move the fibroblast suspension into a $15 \mathrm{~mL}$ conical tube. Ensure that the cells are well mixed and then count on a hemocytometer (see Note 3). Do not centrifuge the fibroblasts at any point.

7. Resuspend 90,000 cells to a final volume of $3 \mathrm{~mL}$ using prewarmed plating media and mix gently but thoroughly mix. The final cell concentration is 30,000 cells/mL. 
8. As shown in Fig. $2 \mathrm{~b}$, pipette $100 \mu \mathrm{L}$ of resuspended fibroblasts into the two wells prepared with $1.9 \mathrm{~mL}$ plating media (from Subheading 3.2, step 4) to seed 3,000 cells per well. Pipette $333 \mu \mathrm{L}$ of resuspended fibroblasts into the two wells prepared with $1.7 \mathrm{~mL}$ plating media to seed 10,000 cells per well. Pipette $1 \mathrm{~mL}$ of resuspended fibroblasts into the two wells prepared with $1 \mathrm{~mL}$ plating media to seed 30,000 cells per well. The final volume in each well is $2 \mathrm{~mL}$.

9. Place the plated cells into a trigas tissue culture incubator with $\mathrm{O} 2$ set to $5 \%$ (low-O2). Once the plate is set down, gently but thoroughly disperse the cells by alternating between an up/down then left/right motion. Repeat the motions two more times. Do not swirl the plate to mix. Incubate the cells overnight.

10. Pipette $7 \mathrm{~mL}$ of reprogramming media (ReproM) into a $15 \mathrm{~mL}$ conical tube and place in the low-O2 incubator with a loosened cap to equilibrate overnight. Do not add bFGF and B18R until the following day.

\subsection{Reprogramming fibroblasts}

Fibroblasts undergoing reprogramming are transfected seven times, every-other-day (days 1, $3,5,7,9,11$, and 13). Reprogramming media is replaced prior to the first transfection (day 1) and each day the cells are not transfected (days 2, 4, 6, 8, 10, 12, 14, 15, 16, 17, 18) (Fig. 3a).

1. Before the day 1 transfection, the fibroblast expansion media which was used for plating must be replaced with ReproM. One hour prior to transfecting the fibroblasts, supplement the preequilibrated ReproM with bFGF to a final concentration of $100 \mathrm{ng} / \mathrm{mL}$ and B18R to a final concentration of $200 \mathrm{ng} / \mathrm{mL}$. Proceeding 1 well at a time, use a $1 \mathrm{~mL}$ pipette to remove the spent $2 \mathrm{~mL}$ of plating medium and replace with $1 \mathrm{~mL}$ of ReproM supplemented with bFGF and B18R. Repeat for each well (see Note 4). Move the plate with cells back into the low-O2 incubator. A media change is not performed on any other days of transfection (i.e. days $3,5,7,9,11,13$ ).

2. Equilibrate an aliquot of the transfection buffer for approximately $1 \mathrm{~h}$ at RT. Do not use a $37^{\circ} \mathrm{C}$ water bath or incubator to warm up the transfection buffer.

3. Remove a single aliquot of reprogramming RNA $(88 \mu \mathrm{L})$ from $-80^{\circ} \mathrm{C}$ and warm to RT for approximately $3-5 \mathrm{~min}$, until thawed. Do not thaw the aliquot at $37^{\circ} \mathrm{C}$. Spin down briefly in a microfuge.

4. Warm the Lipofectamine RNAiMAX to room temperature for approximately 3-5 min. Do not use a $37^{\circ} \mathrm{C}$ water bath or incubator. Invert the closed tube 2-3 times to mix the reagent. Spin down in a microfuge.

5. To prepare the transfection mix (see Fig. 4), transfer $486 \mu \mathrm{L}$ of the room temperature transfection buffer into an RNase-free $1.5 \mathrm{~mL}$ tube. Add $54 \mu \mathrm{L}$ of the RNAiMAX to achieve a final volume of $540 \mu \mathrm{L}$ (includes an excess $12 \mu \mathrm{L}$ to allow for pipetting error). Mix thoroughly by pipetting, do not vortex. Incubate the tube at RT for $1 \mathrm{~min}$. 
6. Add $440 \mu \mathrm{L}$ of the room temperature transfection buffer to the $88 \mu \mathrm{L}$ aliquot of reprogramming RNA. Gently pipette to mix: final volume is $528 \mu \mathrm{L}$ (see Note 5).

7. Add $528 \mu \mathrm{L}$ of the diluted RNAiMAX to the diluted reprogramming RNA. Pipette to mix: final volume is $1056 \mu \mathrm{L}$.

8. Incubate for $15 \mathrm{~min}$ at room temperature to allow the Lipofectamine RNAiMAX to complex with the reprogramming RNA.

9. After the $15 \mathrm{~min}$ incubation, remove the plate with fibroblasts from the low-O2 incubator. Add $168 \mu \mathrm{L}$ of the complexed transfection mix to each well, dropwise throughout the well (see Note 6). Disperse transfection complexes by gently but thoroughly agitating the plate with an up/down then left/right motion. Do not swirl the plate to mix.

10. Place the transfected cells into the tri-gas incubator with $\mathrm{O} 2$ set to $5 \%$ (low-O2). Once the plate is set down, disperse transfection complexes again by gently but thoroughly agitating the plate with an up/down then left/right motion.

11. Pipet $7 \mathrm{~mL}$ of ReproM into a $15 \mathrm{~mL}$ conical tube and place in the low-O2 incubator with loosened cap to equilibrate overnight. Do not add bFGF and B18R until the following day (see Note 7).

12. Monitor expression of mWasabi daily to confirm transfection quality. mWasabi expression should be minimally apparent on day 2 and increase in brightness with each additional transfection.

\subsection{Picking reprogrammed iPSC colonies}

During the reprogramming procedure, fibroblasts rapidly change their morphology (Fig. 3bi), and the formation of iPSC colonies usually occurs by day 18 but may take as long as day 22 (Fig. 3j and Fig. 5).

1. Using an inverted microscope, identify the best plating condition by confirming the presence of well-formed reprogrammed iPSC colonies (Fig. 3j).

2. Prewarm $16 \mathrm{~mL}$ of $\mathrm{mTeSR}$ to $37^{\circ} \mathrm{C}$.

3. Coat all wells of a single 6-well plate with hESC-qualified Matrigel following the manufacturer's instruction. Seal plates with Parafilm and incubate for $1 \mathrm{~h}$ at RT (see Note 8).

4. Aspirate the cell culture medium from the well being used to collect iPSCs. Rinse once with $1 \mathrm{~mL}$ of iPSC passaging reagent and aspirate. Add $1 \mathrm{~mL}$ of iPSC passaging reagent per well and incubate for $4 \mathrm{~min}$ at $37^{\circ} \mathrm{C}$.

5. While the cells are incubating, aspirate the Matrigel from the coated plate and replace with $2 \mathrm{~mL}$ of mTeSR medium per well. Set the plates aside.

6. Gently remove the plate with iPSCs to be picked from the incubator and place in the biosafety cabinet (see Note 9). 
7. Carefully aspirate the iPSC passaging reagent. Very gently add $3 \mathrm{~mL}$ of prewarmed PSC medium, taking care not to dislodge iPSC colonies.

8. Move the plate to an inverted or dissecting scope to better visualize colonies. Prepare a $200 \mu \mathrm{L}$ pipette with a sterile tip. Depress the plunger fully, then use the pipette tip to gently scrape a colony while slowly drawing liquid into the tip to collect the colony. Draw as little medium as possible while picking the iPSC colony.

9. To transfer the colony, pipette up and down 3-4 times in a single well of the prepared plate from Subheading 3.4, step 5. Repeat until six colonies have been picked and transferred into individual wells (see Note 10).

10. Use standard iPSC culture procedures to expand the picked iPSC lines.

\section{Notes}

1. The $\mathrm{pH}$ of the transfection buffer is critical. Ensure the $\mathrm{pH}$ meter is calibrated. $\mathrm{pH}$ fluctuates with temperature, so it is important to allow the Opti-MEM to fully equilibrate to room temperature before adjusting the $\mathrm{pH}$. Reprogramming will be successful if the $\mathrm{pH}$ of Opti-MEM is slightly below 8.2 (between 8.15 and 8.2) but may fail if the $\mathrm{pH}$ is higher than 8.2.

2. The cell density is critical to achieve high reprogramming efficiency, as it is important that the fibroblasts are healthy and rapidly dividing. Plating $2.5 \times 10^{5}$ cells yields a 40-60\% confluency 2 days later, for most fibroblast samples. Adjust accordingly for diseased or senescent cells to attain the desired 40-60\% confluency $48 \mathrm{~h}$ later.

3. A $10 \mathrm{~cm}$ dish of fibroblasts at the correct density should yield approximately $1 \times$ $10^{6} \pm 20 \%$ fibroblasts.

4. Do not use vacuum aspiration, which excessively dries the cells, causes stress, and reduces reprogramming efficiency.

5. Each tube of transfection buffer can be used for two transfections. If this is the first use, tightly close the tube and store at $4^{\circ} \mathrm{C}$. Use for the next transfection.

6. $\quad 168 \mu \mathrm{L}$ of complexed mix contains $1000 \mathrm{ng}$ of modified mRNAs and $20 \mathrm{pmol}$ of miRNAs.

7. After the final transfection (day 13), it is not necessary to equilibrate media overnight.

8. Picking six colonies for expansion is usually sufficient to establish $2-3$ highquality iPSC lines (i.e., karyotypically normal, expresses all pluripotency markers, good morphology, small number of differentiating cells).

9. At this point, cells may be very loosely adhered and can be easily dislodged. Handle the plate gently. 
10. Once the ideal plating density is identified, the reprogramming efficiency is sufficiently high that all six clonal lines can be established from a single reprogrammed well. The second well can be left in culture as backup in case more colonies need to be picked. Alternatively, the second well can be processed for immunohistochemistry for a pluripotency marker such as TRA-1-60 to assess reprogramming efficiency (Fig. 5).

\section{Acknowledgments}

We are grateful for funding support from the National Institutes of Health (P30 AR057212, R21 AR074642 and U01 AR075932). We also thank Epidermolysis Bullosa (EB) Research Partnership, the EB Medical Research Foundation, the Cure EB Charity, Dystrophic Epidermolysis Bullosa Research Association (DEBRA) International and the Gates Frontiers Fund.

\section{Abbreviations:}

$\begin{array}{ll}\text { IPSC } & \text { induced pluripotent stem cell } \\ \text { mod-mRNA } & \text { modified mRNA } \\ \text { MEM } & \text { minimum essential media } \\ \text { FEM } & \text { fibroblasts expansion media } \\ \text { ReproM } & \text { reprogramming media } \\ \text { FBS } & \text { fetal bovine serum } \\ \text { DPBS } & \text { Dulbecco's phosphate buffered saline } \\ \text { bFGF } & \text { basic fibroblast growth factor }\end{array}$

\section{References}

1. Takahashi K, Tanabe K, Ohnuki M, Narita M, Ichisaka T, Tomoda K, Yamanaka S (2007) Induction of pluripotent stem cells from adult human fibroblasts by defined factors. Cell 131 (5):861-872. doi:10.1016/j.cell.2007.11.019 [PubMed: 18035408]

2. Hacein-Bey-Abina S, Von Kalle C, Schmidt M, McCormack MP, Wulffraat N, Leboulch P, Lim A, Osborne CS, Pawliuk R, Morillon E, Sorensen R, Forster A, Fraser P, Cohen JI, de Saint Basile G, Alexander I, Wintergerst U, Frebourg T, Aurias A, Stoppa-Lyonnet D, Romana S, Radford-Weiss I, Gross F, Valensi F, Delabesse E, Macintyre E, Sigaux F, Soulier J, Leiva LE, Wissler M, Prinz C, Rabbitts TH, Le Deist F, Fischer A, Cavazzana-Calvo M (2003) LMO2-associated clonal T cell proliferation in two patients after gene therapy for SCID-X1. Science 302 (5644):415-419. doi:10.1126/science.1088547 [PubMed: 14564000]

3. Junying Y, Kejin H, Kim SO, Shulan T, Stewart R, Slukvin II, Thomson JA (2009) Human induced pluripotent stem cells free of vector and transgene sequences. Science 324:797-802. doi:10.1126/ science.1172482 [PubMed: 19325077]

4. Fusaki N, Ban H, Nishiyama A, Saeki K, Hasegawa M (2009) Efficient induction of transgene-free human pluripotent stem cells using a vector based on Sendai virus, an RNA virus that does not integrate into the host genome. Proc Jpn Acad Ser B Phys Biol Sci 85 (8):348-362. doi:10.2183/ pjab.85.348

5. Warren L, Manos PD, Ahfeldt T, Loh YH, Li H, Lau F, Ebina W, Mandal PK, Smith ZD, Meissner A, Daley GQ, Brack AS, Collins JJ, Cowan C, Schlaeger TM, Rossi DJ (2010) Highly efficient 
reprogramming to pluripotency and directed differentiation of human cells with synthetic modified mRNA. Cell Stem Cell 7:618-630. doi:10.1016/j.stem.2010.08.012 [PubMed: 20888316]

6. Kogut I, McCarthy SM, Pavlova M, Astling DP, Chen X, Jakimenko A, Jones KL, Getahun A, Cambier JC, Pasmooij AMG, Jonkman MF, Roop DR, Bilousova G (2018) High-efficiency RNAbased reprogramming of human primary fibroblasts. Nature Communications 9. doi:10.1038/ s41467-018-03190-3

7. Anokye-Danso F, Trivedi CM, Juhr D, Gupta M, Cui Z, Tian Y, Zhang Y, Yang W, Gruber PJ, Epstein JA, Morrisey EE (2011) Highly efficient miRNA-mediated reprogramming of mouse and human somatic cells to pluripotency. Cell Stem Cell 8:376-388. doi:10.1016/j.stem.2011.03.001 [PubMed: 21474102]

8. Guo S, Zi X, Schulz VP, Cheng J, Zhong M, Koochaki SH, Megyola CM, Pan X, Heydari K, Weissman SM, Gallagher PG, Krause DS, Fan R, Lu J (2014) Nonstochastic reprogramming from a privileged somatic cell state. Cell 156 (4):649-662. doi:10.1016/j.cell.2014.01.020 [PubMed: 24486105]

9. McGrath PS, Diette N, Kogut I, Bilousova G (2018) RNA-based Reprogramming of Human Primary Fibroblasts into Induced Pluripotent Stem Cells. J Vis Exp (141). doi:10.3791/58687

10. Mandal PK, Rossi DJ (2013) Reprogramming human fibroblasts to pluripotency using modified mRNA. Nat Protocols 8:568-582. doi:10.1038/nprot.2013.019 [PubMed: 23429718] 


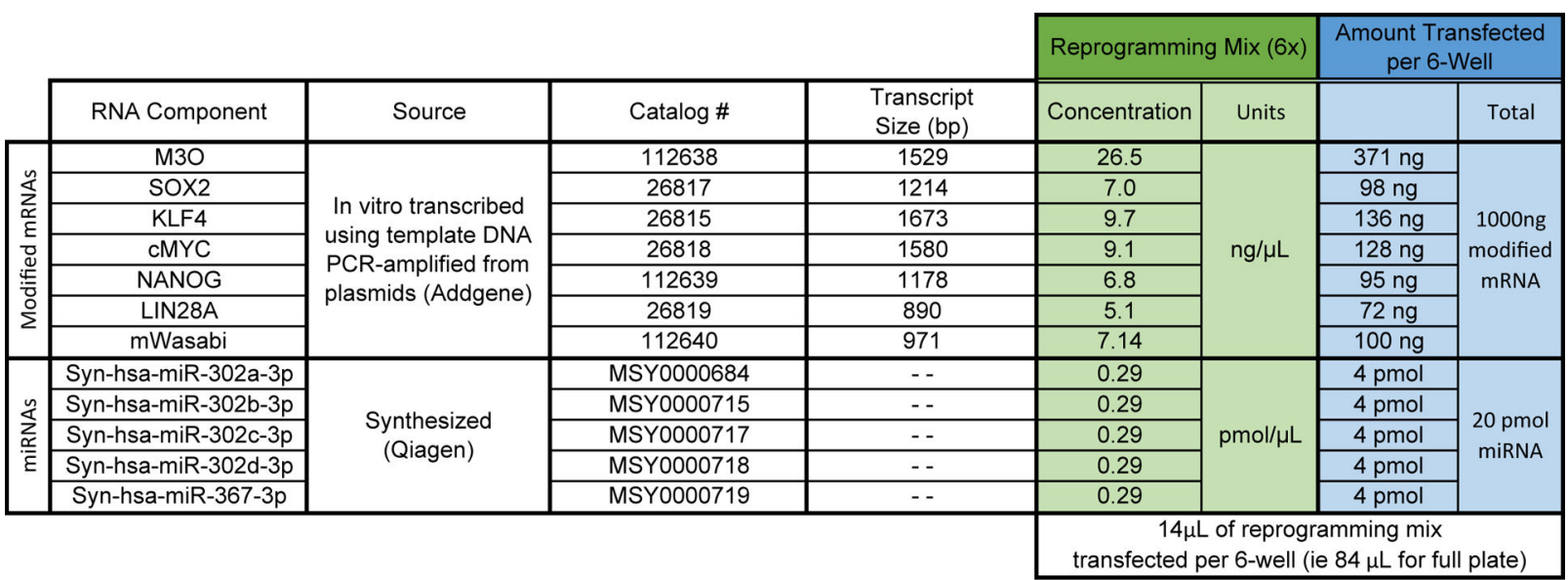

Fig. 1.

Comprehensive list of factors in the reprogramming mix 

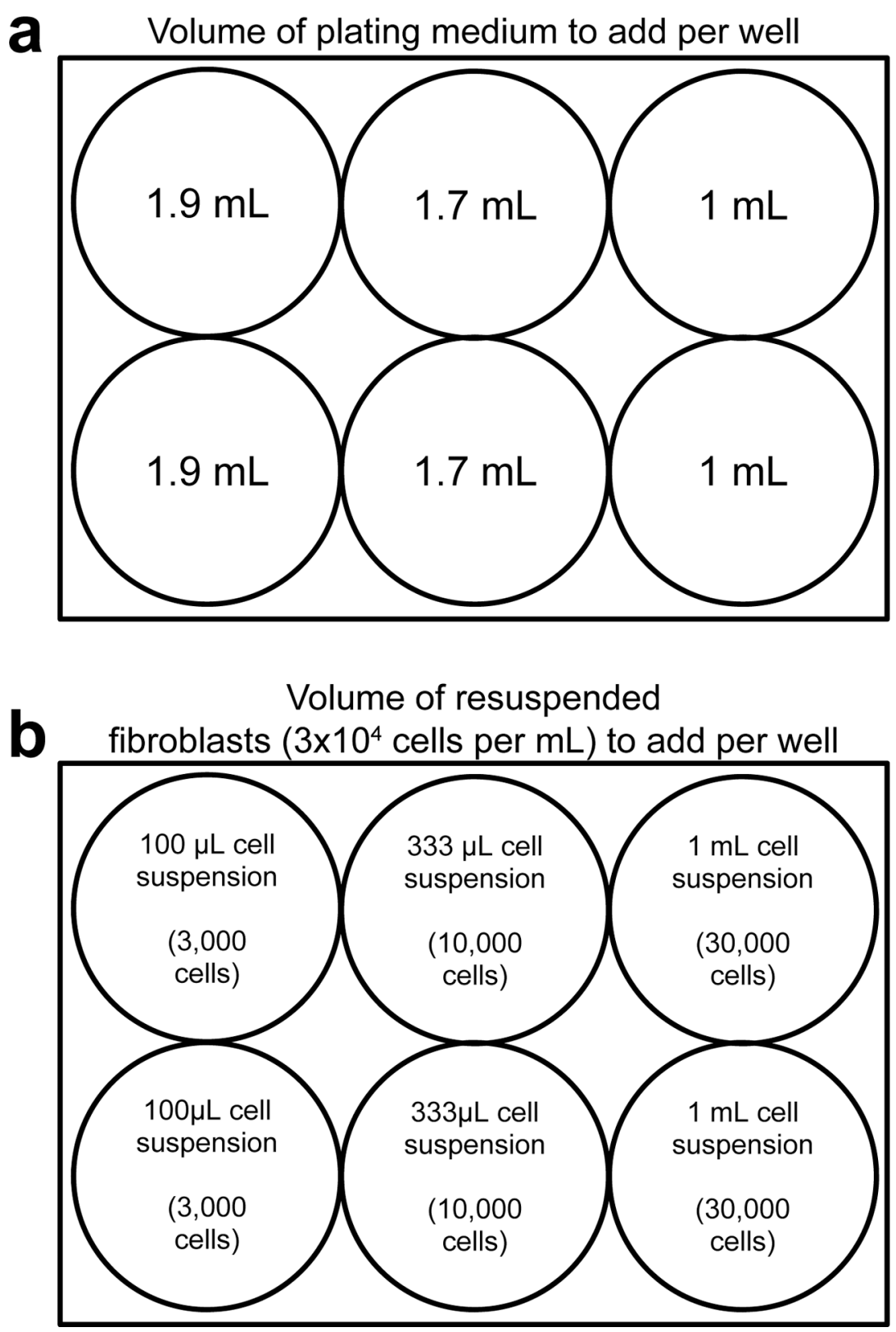

Fig. 2. A procedure for fibroblast plating.

To optimize the efficiency of reprogramming, fibroblasts are plated at multiple densities ranging from 3,000 to 30,000 cells per well. The total plating volume after addition of plating medium (a) and resuspended fibroblasts (b) equals $2 \mathrm{~mL}$ 
a
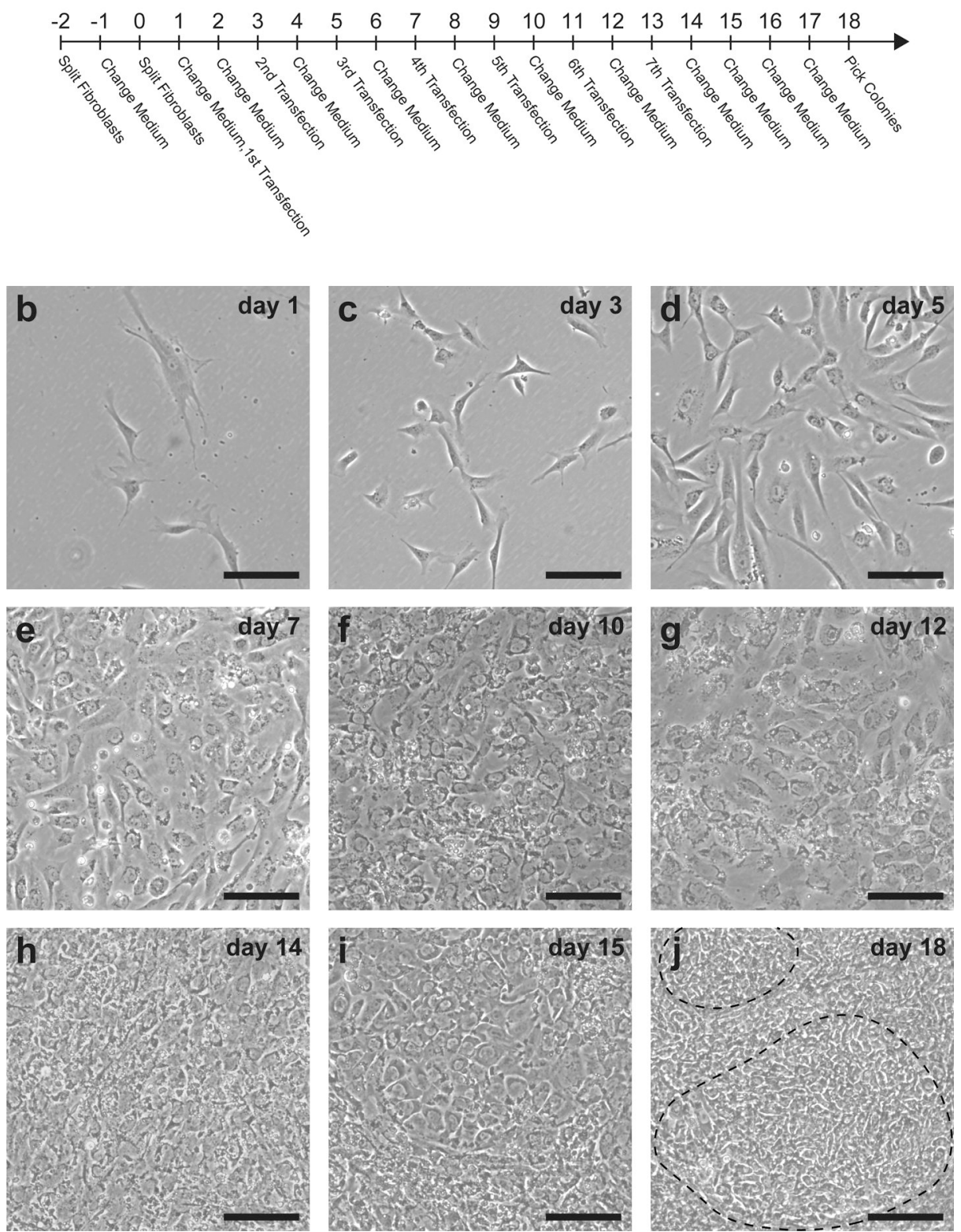

Fig. 3. Visual representation of the reprogramming protocol.

The full reprogramming procedure takes approximately 20 days to pick iPSC colonies for expansion (a). 10,000 fibroblasts plated into one well of a 6-well plate appear relatively sparse on the first day of transfection (b). Following the first transfection, fibroblasts adopt a more compact morphology with fewer cellular projections (c,d). By days 6-7, cells begin to rapidly proliferate (e) and should become confluent (f). Colonies may first be observed on day 12 following the sixth transfection $(\mathrm{g})$ and will grow larger and more clearly distinguishable by day $18(\mathrm{~h}-\mathrm{j})$. Dashed line indicates an iPSC colony. Scale bar $=50 \mu \mathrm{m}$ 
Tube 1 - RNAiMax dilution (1st mix)

\begin{tabular}{|c|c|c|}
\hline Reagent & Concentration & For 6 wells \\
\hline Transfection Buffer & & $486 \mu \mathrm{L}$ \\
\hline RNAiMax (add 2nd) & $10 \mathrm{x}$ & $54 \mu \mathrm{L}$ \\
\hline
\end{tabular}

(incubate $1 \mathrm{~min}$ at room temperature)

\section{Tube 2 - modified mRNA mix (2nd mix)}

\begin{tabular}{|c|c|c|}
\hline Reagent & Concentration & For 6 wells \\
\hline RNA reprogramming mix & $6 \mathrm{x}$ & $88 \mu \mathrm{L}$ \\
\hline Transfection Buffer & & $440 \mu \mathrm{L}$ \\
\hline \multicolumn{2}{|l}{} & $528 \mu \mathrm{L}$ \\
\cline { 3 - 3 }
\end{tabular}

(add equal volume of diluted RNAiMax from Tube 1)

Fig. 4.

An outline of the RNA complexation procedure 

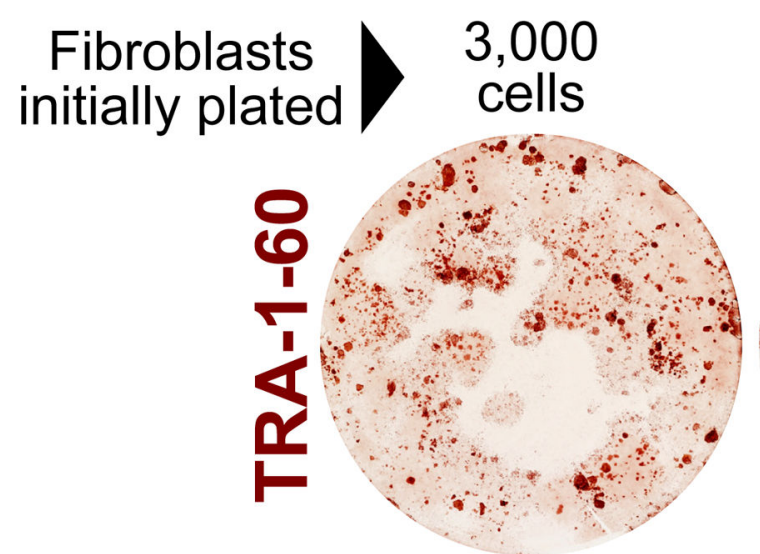

10,000 cells

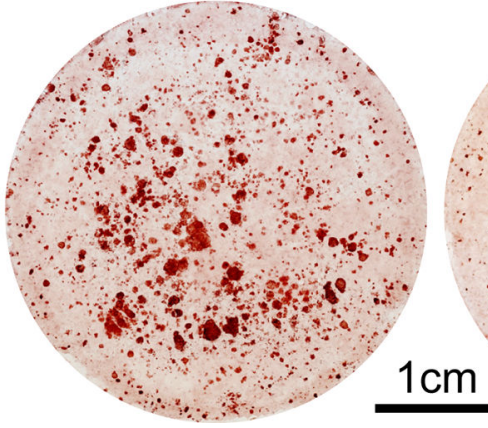

30,000 cells

Fig. 5. Representative TRA-1-60 immunostaining.

$3 \times 10^{3}, 10 \times 10^{3}$, and $30 \times 10^{3}$ dermal fibroblasts derived from a patient with Down syndrome were reprogrammed and stained for the pluripotency marker TRA-1-60. For this cell line, the most robust reprogramming was achieved in the $10 \times 10^{3}$ cell-seeding condition. Plating $3 \times 10^{3}$ fibroblasts was sub-confluent with observable barren patches throughout the well by the end of reprogramming. Seeding $30 \times 10^{3}$ fibroblasts became over-confluent, which also inhibited reprogramming efficiency 